\title{
Halogenated volatile organic compounds in chlorine-bleach- containing household products and implications for their use
}

\author{
Mustafa Odabasi ${ }^{a, *}$, Tolga Elbir ${ }^{a}$, Yetkin Dumanoglu ${ }^{a}$, Sait C. Sofuoglu ${ }^{b}$ \\ ${ }^{a}$ Department of Environmental Engineering, Faculty of Engineering, Dokuz Eylul University, Kaynaklar Campus, 35160 Buca, Izmir, Turkey
}

${ }^{\mathrm{b}}$ Department of Chemical Engineering, Izmir Institute of Technology, 35430 Gulbahce-Urla, Izmir, Turkey

\section{H I G H L I G H T S}

- $\mathrm{CHCl}_{3}$ and $\mathrm{CCl}_{4}$ were the dominating halogenated VOCs in chlorine bleach products.

- Indoor air VOC estimates indicated substantial increases from bleach use.

- Carcinogenic risks from the use of bleach products may be considerably high.

\section{A R T I C L E I N F O}

\section{Article history:}

Received 11 February 2014

Received in revised form

23 April 2014

Accepted 25 April 2014

Available online 26 April 2014

\section{Keywords:}

Chlorine bleach

Chloroform

Carbon tetrachloride

Indoor air

Inhalation exposure
G R A P H I C A L A B S T R A C T

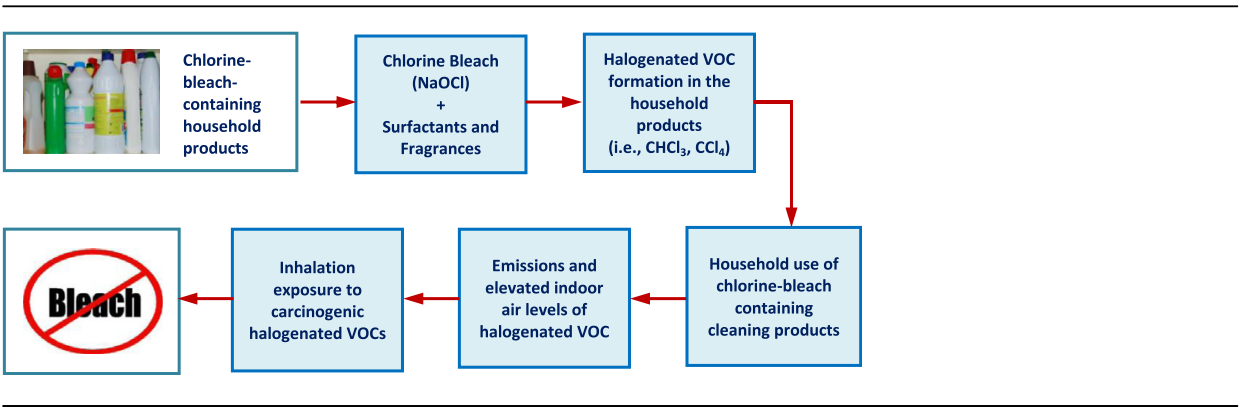

\section{A B S T R A C T}

It was recently shown that substantial amounts of halogenated volatile organic compounds (VOCs) are formed in chlorine-bleach-containing household products as a result of reactions of sodium hypochlorite with organic product components. Use of these household products results in elevated indoor air halogenated VOC concentrations. Halogenated VOCs in several chlorine-bleach-containing household products (plain, $n=9$; fragranced, $n=4$; and surfactant-added, $n=29$ ) from Europe and North America were measured in the present study. Chloroform and carbon tetrachloride were the dominating compounds having average concentrations of $9.5 \pm 29.0$ (average \pm SD) and $23.2 \pm 44.3$ (average $\pm \mathrm{SD}$ ) $\mathrm{mg} \mathrm{L}^{-1}$, respectively. Halogenated VOC concentrations were the lowest in plain bleach, slightly higher in fragranced products and the highest in the surfactant-added products. Investigation of the relationship between the halogenated VOCs and several product ingredients indicated that chlorinated VOC formation is closely related to product composition. Indoor air concentrations from the household use of bleach products (i.e., bathroom, kitchen, and hallway cleaning) were estimated for the two dominating VOCs (chloroform and carbon tetrachloride). Estimated indoor concentrations ranged between 0.5 and $1030(34 \pm 123$, average \pm SD $) \mu \mathrm{g} \mathrm{m}^{-3}$ and $0.3-1124(82 \pm 194$, average \pm SD $) \mu \mathrm{g} \mathrm{m}^{-3}$ for chloroform and carbon tetrachloride, respectively, indicating substantial increases compared to background. Results indicated that indoor air concentrations from surfactant-added products were significantly higher $(p<0.01)$ than other categories. The highest concentrations were from the use of surfactant-added bleach products for bathroom cleaning $\left(92 \pm 228\right.$ and $224 \pm 334 \mu \mathrm{g} \mathrm{m} \mathrm{m}^{-3}$, average \pm SD for chloroform and carbon tetrachloride, respectively). Associated carcinogenic risks from the use of these products were also estimated. The risk levels may reach to considerably high levels for a significant portion of the population especially for those steadily using the surfactant-added bleach products. Based on the results of the present study, it could be recommended that if possible the use of

\footnotetext{
* Corresponding author.

E-mail address: mustafa.odabasi@deu.edu.tr (M. Odabasi).
} 
chlorine bleach containing household products should be avoided. If they are to be used, plain products should be preferred since the chlorinated VOC content increase with the number and amount of additives.

(C) 2014 Published by Elsevier Ltd.

\section{Introduction}

A number of the household cleaning products (bleaches, mildew stain removers, toilet cleaners, cleaning sprays, gels, and scouring powders) contain sodium hypochlorite ( $\mathrm{NaOCl}, \sim 5 \%)$. $\mathrm{NaOCl}$ may be the only active ingredient or it is accompanied by many other chemicals (surfactants, fragrances, $\mathrm{NaCl}$, sodium silicate, sodium hydroxide, antioxidants, and antifoaming agents) (Unilever, 2014; Clorox, 2014; Reckitt Benckiser, 2014; Procter and Gamble, 2014). Generally, the main concern associated with the bleach use has been the release of $\mathrm{Cl}_{2}$ and chloramines as a result of mixing of bleach with other cleaning agents (i.e., acids and ammonia). However, a limited number of studies (Smith, 1994; Odabasi, 2008) have indicated that significant amounts of chlorinated byproducts (especially chloroform and carbon tetrachloride) are formed as a result of the reactions of hypochlorite and organic ingredients of household products. Resulting increase in indoor air concentrations of halogenated VOCs from the use of chlorine-bleach-containing household products was also indicated to be significantly high. It was shown that chloroform $\left(2.9-24.6 \mu \mathrm{g} \mathrm{m}^{-3}\right)$ and carbon tetrachloride $\left(0.25-459 \mu \mathrm{g} \mathrm{m}^{-3}\right)$ concentrations significantly increased during the use of bleach containing products corresponding to during/before concentration ratios of $8-52(25 \pm 14$, average \pm SD $)$ for chloroform and $1-1170$ (146 \pm 367 , average \pm SD) for carbon tetrachloride, respectively (Odabasi, 2008). It was suggested that the bleach use can be important in terms of inhalation/dermal exposure to carbon tetrachloride, chloroform and several other halogenated VOCs (Bondi, 2011; McHugh et al., 2010; Odabasi, 2008). It was also shown that a substantial amount of chloroform is emitted into the indoor air as a result of chlorine bleach use in residential washing machines (Shepherd et al., 1996).

Recent studies (Steinemann, 2009; Odabasi, 2008) have also shown that there are several other ingredients that are not disclosed in detail or at all on chlorine-bleach-containing/other household product labels. Fragrances are examples of such ingredients. Although the fragrances are listed under the product ingredients as an item, an individual "fragrance" in a product can contain up to several hundreds of chemicals, and the composition of an individual fragrance mixture is generally unknown to the public (Steinemann, 2009). The use of household cleaning agents and air fresheners in buildings has raised significant concern since building occupants and cleaning personnel are exposed to various air pollutants that many of them are classified as carcinogens, reproductive toxicants or irritants (Edwards et al., 2006; Nazaroff and Weschler, 2004; IARC, 1999; IARC, 1979). Furthermore, the chemicals emitted from the use of cleaning products may react with other air pollutants to form potentially harmful secondary air pollutants. For example, terpenes can react rapidly with ozone in indoor air producing several secondary gaseous pollutants (i.e., formaldehyde, acetone) and fine particles (Singer et al., 2006; Vartiainen et al., 2006; Nazaroff and Weschler, 2004).

The study by Odabasi (2008) has shown that the use of chlorinebleach-containing household products results in significant indoor halogenated VOC concentrations. However, the study was based on a limited number of products, and VOC concentrations in the products that could be used for modeling the indoor air quality were not measured. Although Odabasi (2008) have suggested that the exposure to carbon tetrachloride, chloroform and several other halogenated VOCs due to bleach use can be important, the associated health risks were not investigated in that study. The objectives of the present study were (i) to determine the concentrations of halogenated VOCs in several chlorine-bleach-containing household products sold in Europe and North America, (ii) to investigate the relationships between the halogenated VOCs and product composition, and (iii) to estimate the indoor air concentrations from the use of these products and associated health risks.

\section{Materials and methods}

Concentrations of halogenated volatile organic compounds (VOCs) in several chlorine-bleach-containing household products $(n=42)$ sold in Europe and North America were measured. The types and commonly used components (declared by the manufacturers) of the products covered in the present study are summarized in Table 1. There are three main categories: plain, fragranced and surfactant-added bleach-containing household products. These products were selected from a large number of similar products that are sold around the world and in Turkey to account for the product type and manufacturer variability.

Table 1

Types and commonly used components of the analyzed products. ${ }^{a}$

\begin{tabular}{|c|c|c|c|}
\hline \multirow[t]{2}{*}{ Component } & \multicolumn{3}{|l|}{ Bleach type } \\
\hline & Plain $(n=9)$ & Fragranced $(n=4)$ & Surfactant-added $(n=29)$ \\
\hline Bleaching agent & \multirow[t]{2}{*}{ Sodium hypochlorite } & \multirow[t]{2}{*}{ Sodium hypochlorite } & Sodium hypochlorite \\
\hline Surfactants & & & $\begin{array}{l}\text { Cetrimonium chloride, cetyl betaine, cocamine oxide, coco-betaine, } \\
\text { lauramine oxide, myristamine oxide, sodium ethylhexyl sulfate, } \\
\text { sodium laurate, sodium xylene sulfonate }\end{array}$ \\
\hline Organic additives & Sodium polyacrylate & Fragrance & $\begin{array}{l}\text { Coconut fatty acid, dye, fragrance, modified polycarboxylate, } \\
\text { sodium polyacrylate }\end{array}$ \\
\hline \multirow[t]{5}{*}{ Inorganic additives } & Hydrochloric acid & Sodium chloride & \multirow{5}{*}{$\begin{array}{l}\text { Potassium iodide, silicone emulsion, sodium carbonate, } \\
\text { sodium chloride, sodium hydroxide } \\
\text { sodium periodate meta, sodium silicate }\end{array}$} \\
\hline & Sodium carbonate & Sodium hydroxide & \\
\hline & Sodium chloride & & \\
\hline & Sodium hydroxide & & \\
\hline & Sodium silicate & & \\
\hline
\end{tabular}

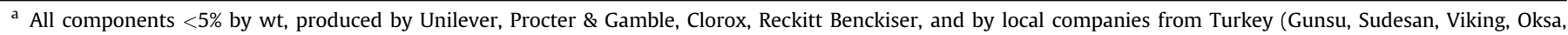
Caglayan, Nazar). 


\subsection{Sample preparation}

Prior to experiments, $40 \mathrm{~mL}$ sample vials were cleaned by washing with detergent, rinsing with tap water, deionized (DI) water, and methanol. Then, they were dried in an oven for several hours at $105{ }^{\circ} \mathrm{C}$. For VOC analysis, bleach samples were diluted 1/ 500 times with pre-purged DI water containing antifoaming agents and ascorbic acid. Tablets consisting of sodium sulfate $(0.97 \mathrm{~g})$ and silicone $(0.03 \mathrm{~g}$ ) were used as antifoaming agent while ascorbic acid $(0.65 \mathrm{~g})$ was used to quench the residual chlorine prior to analysis (U.S. EPA, 1995). After dilution, samples were stand $30 \mathrm{~min}$. Analysis of the diluted samples for residual chlorine indicated that the ascorbic acid amount used and the reaction time were sufficient to effectively quench the chlorine content of the samples.

For elemental analysis $4.0 \mathrm{~mL}$ sample was extracted with an acid-DI water mixture $\left(1 \mathrm{~mL} \mathrm{HNO}_{3}+1 \mathrm{~mL} \mathrm{HCl}+4.5 \mathrm{~mL}\right.$ DI water $)$ in a microwave digester. Then, the samples were filtered through $0.45 \mu \mathrm{m}$ PTFE filters. For residual chlorine, TOC, and TN analysis samples were diluted with $1 / 250,1 / 100$, and $1 / 10$ times with prepurged DI water.

\subsection{Chemical analysis}

Samples were analyzed for their VOC contents using a gas chromatograph (GC) (Agilent 6890N) equipped with a mass selective detector (Agilent 5973 inert MSD, Agilent, Wilmington, DE, USA) and a Purge and Trap sampler (Eclipse 4660, OI Analytical, USA). Samples were purged for $11 \mathrm{~min}$ at $25^{\circ} \mathrm{C}$ using $40 \mathrm{~mL} \mathrm{~min}^{-1}$ of helium flow. Internal trap temperature during sample purge was at $25^{\circ} \mathrm{C}$. The trap was desorbed for $0.7 \mathrm{~min}$ at $200^{\circ} \mathrm{C}$. Then, it was baked for $5 \mathrm{~min}$ at $220^{\circ} \mathrm{C}$. Valve oven and transfer line temperature of the Purge and Trap was $150{ }^{\circ} \mathrm{C}$.

Samples were also analyzed without adding ascorbic acid and by purging at $50{ }^{\circ} \mathrm{C}$ to investigate the effect of temperature on the formation of halogenated VOCs during the use of these products at high temperatures (i.e., laundry and dishwashing).

The chromatographic column was HP5-MS $(30 \mathrm{~m}, 0.25 \mathrm{~mm}$, $0.25 \mu \mathrm{m}$ ) and the carrier gas was helium at $1 \mathrm{~mL} \mathrm{~min}^{-1}$ flow rate and $36 \mathrm{~cm} \mathrm{~s}^{-1}$ linear velocity. The split ratio was 1:40. The inlet temperature was $240^{\circ} \mathrm{C}$. Oven temperature program was: hold for $3 \mathrm{~min}$ at $40{ }^{\circ} \mathrm{C}$, ramp to $120{ }^{\circ} \mathrm{C}$ at $5{ }^{\circ} \mathrm{C} \mathrm{min}{ }^{-1}$, ramp to $200{ }^{\circ} \mathrm{C}$ at $35{ }^{\circ} \mathrm{C} \mathrm{min}^{-1}$, hold $1 \mathrm{~min}$. Ionization mode of the MS was electron impact (EI). Ion source, quadrupole, and GC/MSD interface temperatures were 230,150 , and $280^{\circ} \mathrm{C}$, respectively. The MSD was run in simultaneous scan and selected ion monitoring modes. Compounds were identified based on their retention times (within \pm 0.05 min of the retention time of calibration standard), target and qualifier ions. Identified compounds were quantified using the external standard calibration procedure.

Six levels of VOC solutions containing 76 compounds (hydrocarbons, halogenated, and oxygenated VOCs) in methanol were used as the calibration standards (AccuStandard, USA). Aqueous calibration standards were prepared by spiking $15 \mu \mathrm{L}$ of the calibration standards in methanol into $15 \mathrm{~mL}$ DI water containing antifoaming agent and ascorbic acid (same as the solution used to dilute the samples). Then, they were run at specified conditions to calibrate the analytical system (Purge and Trap-GC-MS). For all compounds, the $r^{2}$ of the calibration curves were $\geq 0.999$.

Elements in the household products ( $\mathrm{Ca}, \mathrm{Cd}, \mathrm{Cr}, \mathrm{Cu}, \mathrm{Fe}, \mathrm{K}, \mathrm{Mg}$, $\mathrm{Mn}, \mathrm{Ni}, \mathrm{Pb}, \mathrm{Sn}$, and $\mathrm{Zn}$ ) were analyzed with Inductively Coupled Plasma-Optical Emission Spectrometer (ICP-OES) (Perkin Elmer DV-2100). Residual chlorine content was analyzed using the Iodometric Method (APHA, 1999). The total organic carbon (TOC) and total nitrogen (TN) content of the bleach products were analyzed using a Total Organic Carbon Analyzer (Shimadzu, TOC-V $\mathrm{V}_{\mathrm{CPN}}$ ).

\subsection{Quality control and quality assurance}

The system performance for VOCs was confirmed daily by analyzing a midrange calibration standard. The relative standard deviation from the initial calibration was $<5 \%$. Analytical precision determined from the analysis of six pairs of duplicate samples as their relative standard deviation ranged between 2 and 5\%.

Instrumental detection limits (IDL) for VOCs were determined from linear extrapolation, based on the lowest standard in calibration curve and using the area of a peak having a signal/noise ratio of 3. IDLs at the defined instrumental conditions ranged between 0.000001 (nonane)-0.00032 (1,2,3-trichloropropane) $\mathrm{mg} \mathrm{L}^{-1}$ (Table S1). Six blanks (solution used to dilute the samples) were analyzed to determine the level of contamination during sample handling and preparation. The limit of detection of the method (MDL, pg) was defined as the mean blank mass plus three standard deviations (MDL $=$ mean blank+3 SD) (Odabasi, 2008). Instrumental detection limits were used for the compounds that were not detected in blanks. Method detection limit (MDL) was determined based on $1 / 500$ sample dilution ranged between 0.0005 (nonane) and 0.160 (1,2-dichloropropane) $\mathrm{mg} \mathrm{L}^{-1}$ (Table S1). In general, VOCs in the samples were substantially higher than the blanks. Average VOC amounts in blanks were $<1.3 \%$ of the amounts found in samples. Average analyte amounts in blanks were $<10 \%$ and $<5 \%$ of the amounts found in TOC and trace element samples, respectively. TN concentrations were not detectable in blanks. Sample quantities exceeding the MDLs were quantified and corrected by subtracting the mean blank amount from the sample amount.

\subsection{Estimation of indoor VOC concentrations from the use of household products}

Indoor air quality concentrations of chloroform and carbon tetrachloride were predicted from the use of 42 different household products during bathroom, kitchen, and hallway cleaning. The following simple box model was used to estimate the indoor air concentrations:

$C_{\mathrm{air}}=C_{\mathrm{b}}+\frac{C_{\mathrm{wp}} V_{\mathrm{p}}}{V_{\mathrm{air}}}$

where $C_{\mathrm{air}}$ is the estimated indoor air concentration $\left(\mu \mathrm{g} \mathrm{m}^{-3}\right), C_{\mathrm{b}}$ is the background indoor air concentration $\left(\mu \mathrm{g} \mathrm{m}^{-3}\right), C_{\mathrm{wp}}$ is the VOC concentration in the household product used $\left(\mu \mathrm{g} \mathrm{m}^{-3}\right), V_{\mathrm{p}}$ is the volume of product used $\left(\mathrm{m}^{3}\right)$, and $V_{\text {air }}$ is the zone volume $\left(\mathrm{m}^{3}\right)$. It was assumed that all VOC content in the product is emitted into the air during the use and it is mixed within the zone volume. Chloroform and carbon tetrachloride have atmospheric lifetimes of 0.55 and 35 years, respectively (Seinfeld and Pandis, 2006). Therefore, in the time frame of the modeling they were assumed to be inert. In order to compare the estimated concentrations to those measured by a recent study (Odabasi, 2008), the assumptions were selected based on those reported by Odabasi (2008) who applied the products according to the manufacturers' suggestions during the experiments. Zone volumes for bathroom, hallway, and kitchen, 15 , 20 and $35 \mathrm{~m}^{3}$ respectively were used. Product amount used was $100 \mathrm{~mL}$, applied directly onto surfaces for bathroom and kitchen cleaning. Same amount was used for hallway cleaning simulation. In accordance with Odabasi (2008), it was assumed that $100 \mathrm{~mL}$ of product was diluted in $5 \mathrm{~L}$ of water and $1 \mathrm{~L}$ of this mixture was applied to the floor.

Odabasi (2008) measured VOC concentrations before, during, and after the use of several bleach products. It was reported that average concentrations before the use of products were $0.41 \mu \mathrm{g} \mathrm{m}^{-3}$ 
for chloroform and $0.27 \mu \mathrm{g} \mathrm{m}^{-3}$ for carbon tetrachloride. These concentrations were used as the background concentrations in the present study.

\subsection{Estimation of carcinogenic risks for inhalation exposure}

Carcinogenic risk associated with inhalation exposure to a chemical was calculated by:

$R=C \times \mathrm{UR} \times F$

where $R$ is the probability of excess lifetime cancer risk, $C$ is indoor air concentration of the chemical of interest $\left(\mu \mathrm{g} \mathrm{m}^{-3}\right)$, and UR is the Unit Risk $\left(\mu \mathrm{g} \mathrm{m}^{-3}\right)^{-1}$. UR is the upper-bound excess lifetime cancer risk of an average adult estimated to result from continuous exposure to an agent at a concentration of $1 \mu \mathrm{g} / \mathrm{m}^{3}$ in air. Values of the UR were obtained as $2.3 \times 10^{-5}$ for chloroform and $6.0 \times 10^{-6}$ for carbon tetrachloride from Integrated Risk Information System of the U.S. EPA (U.S. EPA, 2014). For exposures that would not last as long as a lifetime (assumed as 70 years), a correction factor $(F)$ based on the frequency and duration of the exposure, should be incorporated into the risk estimation, which is the ratio of the exposure length over the exposure duration to the lifetime. The recommended exposure durations are 30 and 25 years for residential and occupational inhalation (Masters and Ela, 2008). The 95th percentile Residential Occupancy Period and Current Residence Time are 33 and 46 years (U.S. EPA, 2011). Cleaning may be both residential and occupational activity, which may be a lifelong activity for some people. Housewives clean their houses up to the ages that they cannot perform these activities anymore. In order to reflect these special properties regarding to cleaning, we selected a longer than recommended exposure duration of 40 years for our exposure scenarios. Two exposure scenarios were constructed for household use of the cleaning products: the median and the 95th percentile scenarios as estimates of central tendency and upperbound risks. The median scenario uses the median concentration and the median exposure time (length), while the 95th percentile scenario uses the 95th percentile values. The median and 95th percentile concentrations are estimated from the concentrations modeled in this study one set each for plain, fragranced, and surfactant-added products. The corresponding exposure times were obtained from the U.S. EPA (U.S. EPA, 2011; U.S. EPA, 1987), which lists two types of exposure times; (i) as time performing household tasks, and (ii) time product groups most frequently used for household cleaning, which are listed in Table S12, along with the values of the calculated correction factor for the two exposure scenarios.

\section{Results and discussion}

Concentrations of halogenated volatile organic compounds (VOCs) in several chlorine-bleach-containing household products ( $n=42$ ) were measured and the relationships between the halogenated VOCs and product ingredients were investigated. Associated carcinogenic risks from the use of these products were also estimated for chloroform and carbon tetrachloride using modeled indoor air concentrations and unit risk factors.

\subsection{Halogenated VOC concentrations in household products}

Chloroform and carbon tetrachloride were the dominating halogenated VOCs in investigated chlorine-bleach-containing household products $(n=42)$, having average concentrations of $9.5 \pm 29.0$ and (average \pm SD) $23.2 \pm 44.3$ (average \pm SD) $\mathrm{mg} \mathrm{L}^{-1}$, respectively (Table 2 ).
Table 2

Halogenated VOC concentrations $\left(\mathrm{mg} \mathrm{L}^{-1}\right)$ in chlorine-bleach-containing household products.

\begin{tabular}{llccclr}
\hline & MIN & MAX & AVG & SD & GM & n \\
\hline 1,1-Dichloroethene & 0.003 & 0.52 & 0.22 & 0.19 & 0.10 & 23 \\
1,1-Dichloroethane & 0.002 & 0.73 & 0.06 & 0.15 & 0.02 & 23 \\
1,2-Dichloropropane & 0.030 & 0.74 & 0.18 & 0.25 & 0.10 & 7 \\
2,2-Dichloropropane & 0.02 & 0.40 & 0.21 & 0.27 & 0.08 & 2 \\
Chloroform & 0.08 & 154 & 9.5 & 29.0 & 1.1 & 42 \\
1,2-Dichloroethane & 0.03 & 0.07 & 0.05 & 0.02 & 0.05 & 2 \\
Carbon tetrachloride & 0.01 & 169 & 23.2 & 44.3 & 1.3 & 42 \\
Trichloroethene & 0.004 & 0.01 & 0.006 & 0.003 & 0.006 & 5 \\
Bromodichloromethane & 0.01 & 0.05 & 0.02 & 0.012 & 0.02 & 11 \\
Trichloronitromethane & 0.02 & 0.36 & 0.15 & 0.09 & 0.12 & 21 \\
2-Chloro-2-nitropropane & 0.02 & 0.26 & 0.09 & 0.09 & 0.06 & 6 \\
Chlorobenzene & 0.003 & 0.007 & 0.005 & 0.002 & 0.005 & 10 \\
1,2-Dichlorobenzene & 0.003 & 0.03 & 0.014 & 0.006 & 0.01 & 40 \\
1,3-Dichlorobenzene & 0.004 & 0.02 & 0.008 & 0.003 & 0.008 & 29 \\
Hexachlorethane & 0.02 & 0.11 & 0.04 & 0.03 & 0.04 & 9 \\
\hline
\end{tabular}

MIN: Minimum, MAX: Maximum, AVG: Average, SD: Standard deviation, GM: Geometric mean, $n$ : Number of samples above MDL.

Halogenated VOC concentrations were the lowest in plain bleach, slightly higher in fragranced products and the highest in the surfactant-added ones (i.e., thick liquids and gels) (Fig. 1). The number of the detected compounds is also significantly higher $(n=15)$ in surfactant-added products compared to plain $(n=5)$ and fragranced $(n=4)$ products. Chloroform and carbon tetrachloride concentrations were relatively lower in plain bleach $\left(0.06-55.4,0.007-0.06 \mathrm{mg} \mathrm{L}^{-1}\right)$ and fragranced products $(6.2-$ $\left.10.3,0.013-0.76 \mathrm{mg} \mathrm{L}^{-1}\right)$ and the high in the surfactant-added ones (i.e., thick liquids and gels) (4.7-106, 0.03-199 $\left.\mathrm{mg} \mathrm{L}^{-1}\right)$. In a previous study (Smith, 1994), it was reported that plain bleach contained $0.01-0.4 \mathrm{mg} \mathrm{L}^{-1}$ chloroform and $0.005-0.05 \mathrm{mg} \mathrm{L}^{-1}$ carbon tetrachloride while the concentration ranges of chloroform and carbon tetrachloride for fragranced products were $0.2-10 \mathrm{mg} \mathrm{L}^{-1}$ and $0.08-8.0 \mathrm{mg} \mathrm{L}^{-1}$, respectively. Other hypochlorite products that contained surfactants, or surfactants and fragrance, showed $0.5-30 \mathrm{mg} \mathrm{L}^{-1}$ of chloroform and $1-15 \mathrm{mg} \mathrm{L}^{-1}$ of carbon tetrachloride (Smith, 1994). These concentrations were substantially lower than those measured in the present study. It should be noted that the present study was conducted $\sim 20$ years after the study by Smith (1994) and product contents may have been changed. Different VOC levels measured in these studies may be due to the change of product contents.

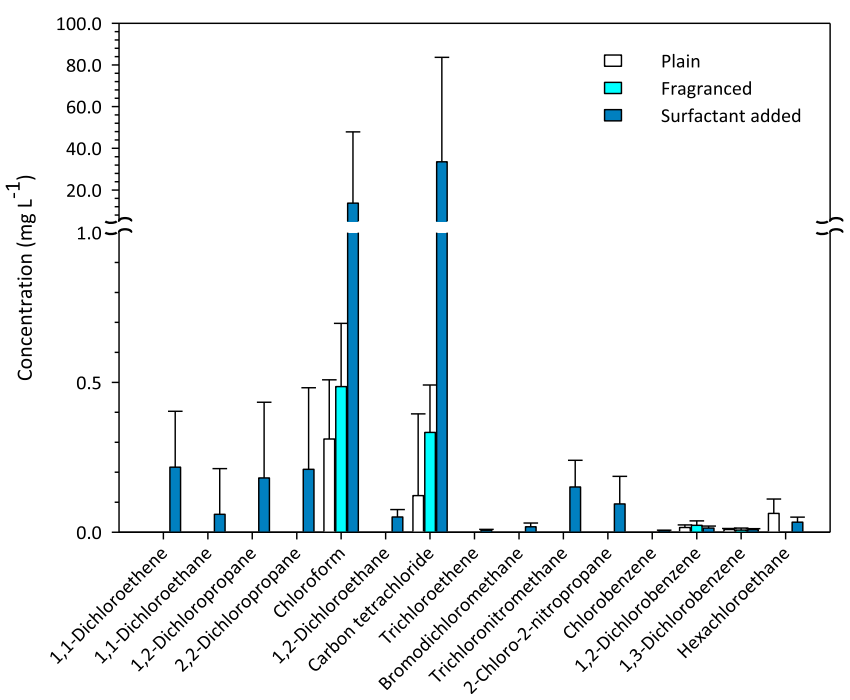

Fig. 1. Average halogenated VOC concentrations in different classes of products. 
Several hydrocarbons and oxygenated VOCs in these products were also determined. Most of the analyzed compounds are fragrance components that were selected among those identified in the chlorine-bleach-containing household products in a previous study (Odabasi, 2008). Tetrahydrolinalool, 2-(1,1-dimethylethyl)cyclohexanol, eucalyptol, dihydromyrcenol, and camphor were the most frequently detected oxygenated VOCs while decane, dodecane, p-isopropyl toluene, 1-dodecene, and nonane were the most frequently detected hydrocarbons. Eucalyptol $\left(105 \pm 148 \mathrm{mg} \mathrm{L}^{-1}\right.$, average $\pm \mathrm{SD})$ and tetrahydrolinalool $\left(86.5 \pm 145 \mathrm{mg} \mathrm{L^{-1 }}\right.$, average \pm SD) were the leading oxygenated VOCs while p-isopropyl toluene $\left(2.3 \pm 6.6 \mathrm{mg} \mathrm{L}^{-1}\right.$, average $\left.\pm \mathrm{SD}\right)$ and dodecane $\left(2.2 \pm 4.1 \mathrm{mg} \mathrm{L}^{-1}\right.$, average $\left.\pm \mathrm{SD}\right)$ were the hydrocarbons with the highest average concentrations (Table 3 ).

Samples were also analyzed without adding ascorbic acid to quench the residual chlorine and by purging at $50{ }^{\circ} \mathrm{C}$ to investigate the effect of temperature on the formation of halogenated VOCs during the use of these products at high temperature applications (i.e., laundry and dishwashing). For all analyzed products, most of the halogenated VOC concentrations at $50{ }^{\circ} \mathrm{C}$ were similar to those measured at $25{ }^{\circ} \mathrm{C}$ except for chloroform and bromodichloromethane that were 2.2 and 2.7 times higher at $50{ }^{\circ} \mathrm{C}$ (Fig. 2a). The increase in chloroform concentrations was even much more pronounced for plain products (52 times) at $50{ }^{\circ} \mathrm{C}$. The number of detected compounds was also increased from 5 to 9 at $50{ }^{\circ} \mathrm{C}$ (Fig. 2b). During the analysis at $25^{\circ} \mathrm{C}$, five samples were reanalyzed without removing them from the purge and trap sampler to check the efficiency of sample purging. No detectable amounts of any of the compounds analyzed were found after the second purge indicating that the first purge completely removed VOCs from the sample. Therefore, substantially higher VOC amounts found at $50{ }^{\circ} \mathrm{C}$ could not be attributed to increase in Henry's law constants at higher temperature, favoring a more effective purge. Instead, higher concentrations may be due to increased rates of halogenated VOC forming reactions at $50{ }^{\circ} \mathrm{C}$. On the other hand, concentrations of some compounds (i.e., 2-chloro2-nitropropane, hexachlorethane, carbon tetrachloride) decreased

Table 3

Oxygenated and other VOC concentrations $\left(\mathrm{mg} \mathrm{L}^{-1}\right)$ in chlorine-bleach-containing household products.

\begin{tabular}{|c|c|c|c|c|c|c|}
\hline & MIN & MAX & AVG & SD & GM & $\mathrm{n}$ \\
\hline \multicolumn{7}{|l|}{ Oxygenated VOCs } \\
\hline Isocineole & 0.02 & 64.4 & 8.3 & 18.1 & 1.0 & 13 \\
\hline p-methylanisole & 0.07 & 0.21 & 0.14 & 0.10 & 0.12 & 2 \\
\hline Eucalyptol & 0.05 & 565 & 105 & 148 & 15.7 & 22 \\
\hline Dihydromyrcenol & 0.13 & 85.2 & 13.7 & 22.2 & 3.9 & 21 \\
\hline L-fenchone & 0.14 & 3.0 & 0.86 & 0.75 & 0.60 & 17 \\
\hline Tetrahydrolinalool & 0.03 & 574 & 86.5 & 145 & 19.5 & 29 \\
\hline D-fenchyl alcohol & 0.08 & 2.5 & 0.98 & 1.0 & 0.58 & 7 \\
\hline 2-tert-butylcyclohexanone & 0.03 & 0.21 & 0.08 & 0.06 & 0.07 & 11 \\
\hline Trans-dihydro-b-terpineol & 0.06 & 58.8 & 10.3 & 15.9 & 2.7 & 18 \\
\hline Camphor & 0.16 & 138 & 32.7 & 48.8 & 3.8 & 20 \\
\hline Isoborneol & 0.27 & 85.3 & 19.9 & 26.8 & 6.2 & 18 \\
\hline $\begin{array}{l}\text { 2-(1,1-dimethylethyl)- } \\
\text { cyclohexanol }\end{array}$ & 0.06 & 64.0 & 8.5 & 15.2 & 2.3 & 27 \\
\hline \multicolumn{7}{|l|}{ Hydrocarbons } \\
\hline Octane & 0.001 & 1.3 & 0.20 & 0.33 & 0.07 & 24 \\
\hline Propylcyclopentane & 0.001 & 0.25 & 0.04 & 0.07 & 0.02 & 16 \\
\hline Nonane & 0.001 & 2.1 & 0.26 & 0.50 & 0.07 & 25 \\
\hline Alpha-pinene & 0.014 & 0.37 & 0.07 & 0.10 & 0.05 & 22 \\
\hline Decane & 0.001 & 4.7 & 0.82 & 1.08 & 0.36 & 41 \\
\hline p-isopropyl toluene & 0.001 & 39.5 & 2.3 & 6.6 & 0.16 & 38 \\
\hline 1-Dodecene & 0.001 & 7.6 & 1.4 & 2.1 & 0.44 & 37 \\
\hline Dodecane & 0.002 & 17.3 & 2.2 & 4.1 & 0.52 & 41 \\
\hline
\end{tabular}

MIN: Minimum, MAX: Maximum, AVG: Average, SD: Standard deviation, GM: Geometric mean, $n$ : Number of samples above MDL. at $50{ }^{\circ} \mathrm{C}$ suggesting that they were degraded at higher temperatures.

Trace elemental contents of the household products are presented in Table S2 along with their TOC, TN, and free chlorine contents that also may affect the formation of halogenated VOCs. Trace element concentrations were variable and $\mathrm{Ca}, \mathrm{K}$, and $\mathrm{Mg}$ had the highest concentrations $(0.65-302,0.56-440$, and $0.08-$ $10.5 \mathrm{mg} \mathrm{L}^{-1}$, respectively) followed by $\mathrm{Zn}$ and $\mathrm{Fe}(0.02-1.4$ and $0.02-1.0 \mathrm{mg} \mathrm{L}^{-1}$, respectively). Concentrations of the remaining elements ( $\mathrm{Cd}, \mathrm{Cr}, \mathrm{Cu}, \mathrm{Mn}, \mathrm{Ni}, \mathrm{Pb}$, and $\mathrm{Sn}$ ) were generally lower than $0.1 \mathrm{mg} \mathrm{L}^{-1}$. TOC and TN contents were also highly variable $(0.002-$ $2.7 \%$ and $0.3-488 \mathrm{mg} \mathrm{L}^{-1}$, respectively) due to variability of fragrance and surfactant content, or due to the type of surfactant (i.e., nitrogen containing surfactants like lauramine oxide, myristamine oxide, cetyl betaine, and cetrimonium chloride). The average free chlorine content was $3.4 \pm 1.8 \%$ (average \pm SD) and relatively less variable compared to other components.

(a) All products

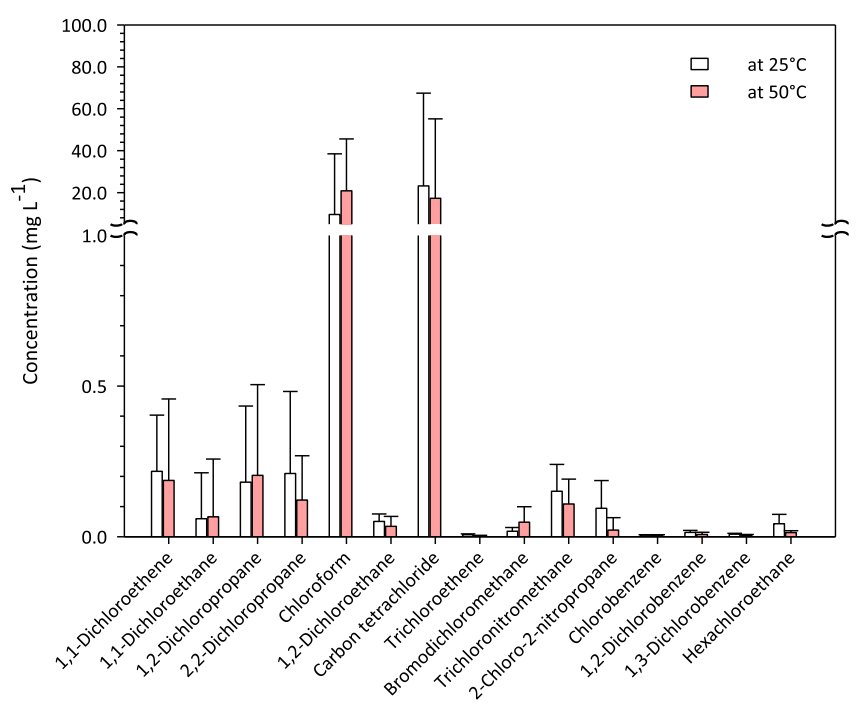

(b) Plain products only

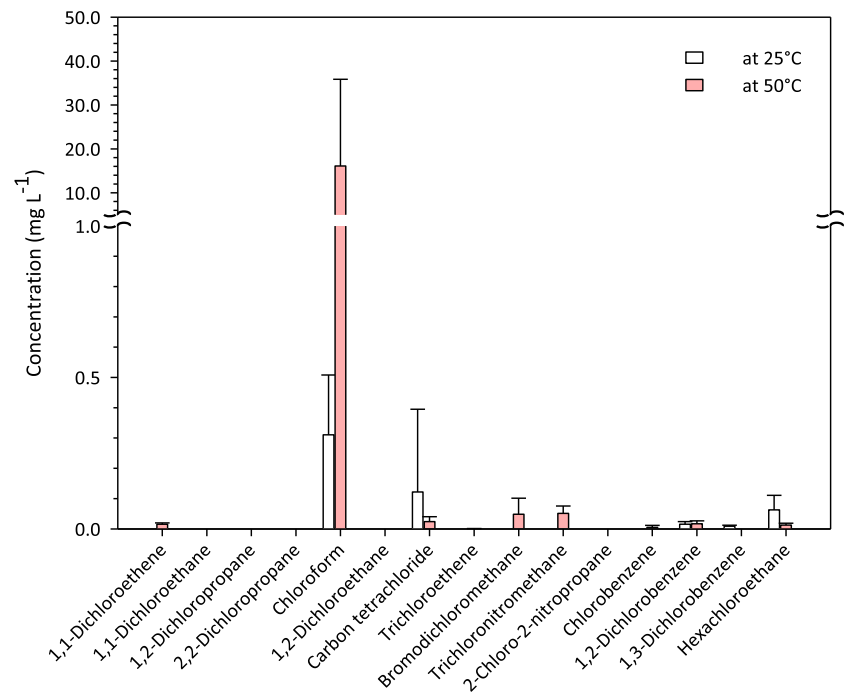

Fig. 2. Comparison of halogenated VOC concentrations measured in bleach containing household products at $25^{\circ} \mathrm{C}$ and $50{ }^{\circ} \mathrm{C}$. 


\subsection{Effect of product composition on halogenated VOC content}

It was suggested that some elements may catalyze the halogenated VOC formation during drinking water chlorination (Ye et al, 2009; Fu et al., 2009). Similarly, it is also possible that elemental composition of the bleach products may affect the formation of halogenated VOCs. Therefore, the relationship between the halogenated VOCs and product ingredients were investigated using backward stepwise linear regression analysis. This analysis was applied for the seven most frequently detected ( $>21$ times) chlorinated compounds (1,1-dichloroethene, 1,1-dichloroethane, chloroform, carbon tetrachloride, trichloronitromethane, 1,2dichlorobenzene, and 1,3-dichlorobenzene). Prior to regression analysis, the dataset was censored using the $1 / 2$ of the MDL values for the non-detected compounds. Only the parameters with $p<0.05$ were retained in the overall models. Measured product components explained the $61.5 \%-99.6 \%$ variability of chlorinated VOC concentrations (Table S3, S4-S10). The mostly associated components with the chlorinated VOC formation were the oxygenated VOCs. Some of them positively correlated with chlorinated VOCs (isocineole, eucalyptol, tetrahydrolinalool, and 2-tertbutylcyclohexanone) while the correlations were negative for others [D-Fenchyl alcohol, trans-dihydro-b-terpineol, isoborneol, and 2-(1,1-dimethylethyl)-cyclohexanol)]. Among the remaining components, generally octane and dodecane positively correlated with chlorinated VOCs while nonane was negatively correlated. The major product components (i.e., free chlorine, TOC, and TN) were not effective in chlorinated VOC formation. This could be explained with the fact that free chlorine content was generally high enough to form chlorinated VOCs (i.e., >2.0\%) and not largely variable. The lack of correlation between the TOC content and chlorinated VOCs may be due to fact that, not all organic compounds, only ones with some specific moieties (i.e., phenolic) take part in chlorinated VOC formation pathways (Gallard and von Gunten, 2002). Some trace elements were effective on halogenated VOC formation. Ca, K, and $\mathrm{Mg}$ were generally negatively correlated while $\mathrm{Cd}, \mathrm{Ni}$, and $\mathrm{Pb}$ were positively correlated. Recently, a similar negative effect of some trace elements ( $\mathrm{Ca}, \mathrm{Mg}$, and $\mathrm{Fe}$ ) on trihalomethane formation in chlorinated drinking waters was reported (Ye et al., 2009). The results of multiple linear regression analysis clearly indicated that chlorinated VOC formation is closely related to product composition. Some product components especially oxygenated VOCs promote chlorinated VOC formation while some components have an inhibitory effect. It should be noted that, there are several product components which were not quantified in this study that could be effective on chlorinated VOC formation.

The results reported here have some important implications on product compositions. For example, manufacturers may prefer to include the components having inhibitory effect on chlorinated VOC formation rather than those promoting. Main concern of the manufacturers in product formulation is to maximize the effect of active chlorine content. Since reactive product components reduce the active chlorine content, excluding them from product formulations is also consistent with the industrial standpoint.

\subsection{Estimated indoor concentrations from the use of household products}

Indoor air concentrations of chloroform and carbon tetrachloride were predicted from the use of household products for bathroom, kitchen, and hallway cleaning. These two compounds were selected since they are the dominating halogenated VOCs in the household products and they are known to be carcinogenic (IARC, 1999; IARC, 1979), having available inhalation risk factors (U.S. EPA, 2014).
Model predictions showed that indoor VOC concentrations significantly increased after the cleaning applications. Estimated indoor concentrations from the use of selected bleach products $(n=42)$ ranged between 0.5 and $1030 \mu \mathrm{g} \mathrm{m}^{-3}\left(34 \pm 123, \mu \mathrm{g} \mathrm{m}^{-3}\right.$, average \pm SD) and $0.3-1124 \mu \mathrm{g} \mathrm{m}^{-3}\left(82 \pm 194 \mu \mathrm{g} \mathrm{m} \mathrm{m}^{-3}\right.$, average \pm SD) for chloroform and carbon tetrachloride, respectively (Table S11). Fig. 3 shows the average concentrations of each product category (plain, fragranced and surfactant-added) for the three VOCs. Results indicated that indoor air concentrations from surfactant-added products were significantly higher $(p<0.01)$ than other categories.

The highest concentrations were from the use of surfactantadded bleach products for bathroom cleaning (see the Table S11). The average chloroform and carbon tetrachloride concentrations for this case were $92 \pm 228$ and $224 \pm 334 \mu \mathrm{g} \mathrm{m}^{-3}$ (average \pm SD), respectively. Comparably high chloroform and carbon tetrachloride concentrations ( 1340 and $260 \mu \mathrm{g} \mathrm{m}^{-3}$ ) were reported from cleaning $7.7 \mathrm{~m}^{2}$ ceramic tile shower walls with a mildew remover in a $7.4 \mathrm{~m}^{3}$ room (Smith, 1994).

Odabasi (2008) has measured indoor air halogenated VOC concentrations resulting from the use of four selected household products (i.e., one plain and three surfactant-added). The compositions of the same products were also analyzed in the present study. Estimated indoor air concentrations from the use of these four products were compared to those measured by Odabasi (2008) by linear regression. This comparison indicated a very good agreement between the measured and estimated concentrations $\left(r^{2}=0.92\right.$ and 0.96 for chloroform and carbon tetrachloride, $p<0.01, n=20$ ). The slope of the modeled vs. measured regression line was 1.11 for carbon tetrachloride indicating an excellent agreement. However, for chloroform the slope was 0.77 indicating that the model slightly underpredicted the indoor concentrations. Chlorinated byproducts also form when bleach-containing cleaning products react with organic matter present on dirty surfaces (Smith, 1994; Nazaroff and Weschler, 2004; Odabasi, 2008). Therefore, underpredicted chloroform concentrations may be due to additional chloroform formation during surface cleaning that could not be accounted by the model used in the present study.

\subsection{Carcinogenic risk assessment for inhalation exposure}

Carcinogenic risks were estimated for two exposure scenarios: median and 95th percentile exposures. Two types of exposure times were used in each scenario; (i) time performing household tasks, and (ii) time product groups most frequently used for household cleaning (see Materials and Methods section). Estimated carcinogenic risks for the two exposure scenarios based on household cleaning product use time are presented in Table 4. The risks based on the time performing household activity are provided in Table S13. Risks based on cleaning product use time are slightly higher than those based on time performing household tasks. The carcinogenic risks were also estimated for exposure to background concentrations. The mean background concentration levels, reported as $0.41 \mu \mathrm{g} \mathrm{m}^{-3}$ for chloroform and $0.27 \mu \mathrm{g} \mathrm{m}^{-3}$ for carbon tetrachloride (Odabasi, 2008), were used to estimate the background risks. Carcinogenic risks due to lifetime exposure to the background concentrations are $9.4 \times 10^{-6}$ and $1.6 \times 10^{-6}$ for chloroform and carbon tetrachloride, respectively. Both of the risk values are higher than the general acceptable risk level of $1.0 \times 10^{-6}$ (Legay et al., 2011; Health Canada, 1998). Although all median scenario risk values are $<1.0 \times 10^{-6}$ for both of the chemicals, these risks are additional to the background risks. On the other hand, all are greater than or equal to the acceptable risk level in the 95th percentile exposure scenario. The risk levels for both of the chemicals in this scenario for surfactant-added products surpass a 

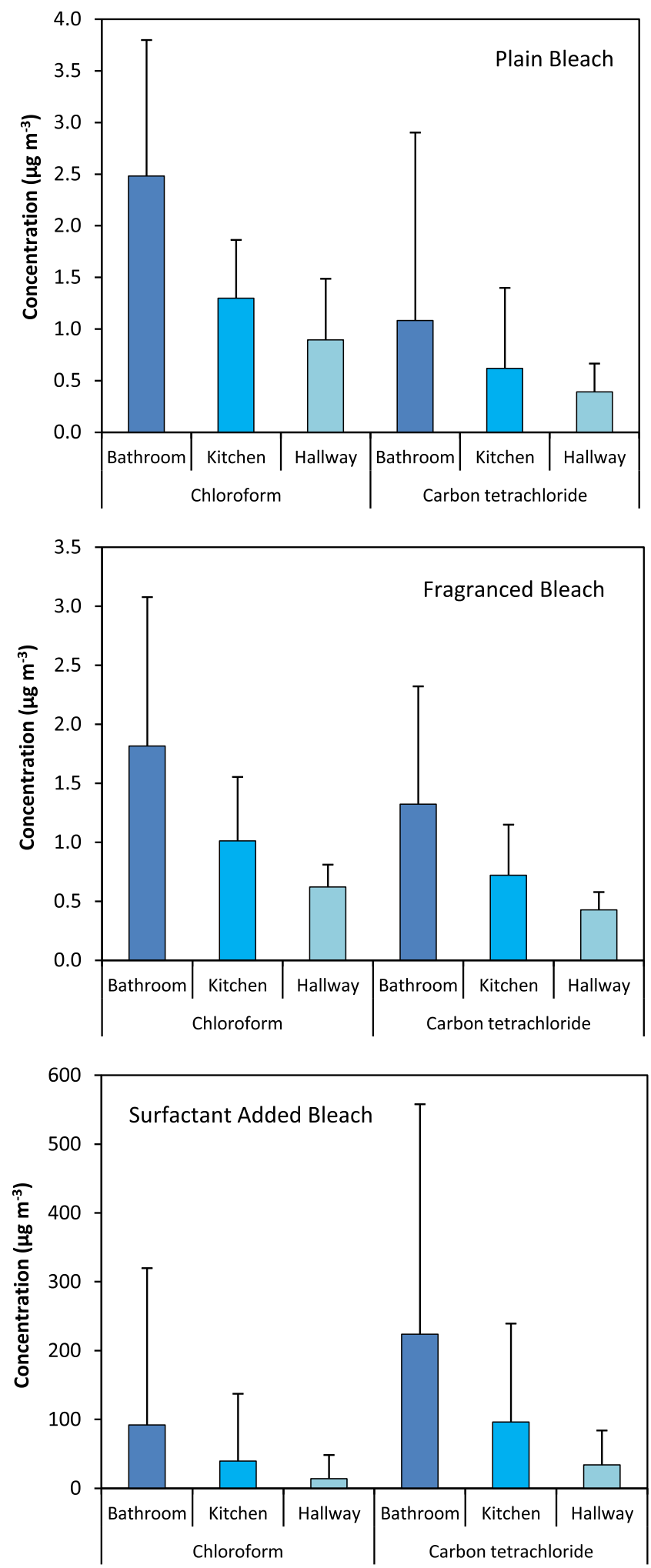

Fig. 3. Average indoor air quality concentrations of chloroform and carbon tetrachloride for three product categories.

higher acceptable risk level $\left(1.0 \times 10^{-4}\right)$ preferred for some pollutants difficult to deal with, such as arsenic (Legay et al., 2011; Health Canada, 1998). Values of ratio of the median risk due to product use to the risk due to the mean background exposure are
Table 4

Estimated carcinogenic risks associated with the product use for two exposure scenarios.

\begin{tabular}{|c|c|c|c|c|}
\hline & \multicolumn{2}{|c|}{ Median exposure scenario } & \multicolumn{2}{|c|}{$95^{\text {th }}$ Percentile exposure scenario } \\
\hline & Chloroform & $\begin{array}{l}\text { Carbon } \\
\text { tetrachloride }\end{array}$ & Chloroform & $\begin{array}{l}\text { Carbon } \\
\text { tetrachloride }\end{array}$ \\
\hline Plain & $1.5 \times 10^{-7}$ & $1.3 \times 10^{-8}$ & $7.3 \times 10^{-6}$ & $1.0 \times 10^{-6}$ \\
\hline Fragranced & $1.3 \times 10^{-7}$ & $2.1 \times 10^{-8}$ & $4.7 \times 10^{-6}$ & $9.9 \times 10^{-7}$ \\
\hline $\begin{array}{l}\text { Surfactant- } \\
\text { added }\end{array}$ & $7.9 \times 10^{-7}$ & $8.1 \times 10^{-7}$ & $4.7 \times 10^{-4}$ & $2.4 \times 10^{-4}$ \\
\hline
\end{tabular}

presented in Table S13. The background risk was estimated for the same exposure length as for product use so that the two are comparable. Ratio values are $<2.5$ for plain and perfumed products while they are $>13$ for surfactant-added products with a highest value of 86 for carbon tetrachloride. In summary, based on the upper-bound estimates, it can be argued that carcinogenic risks may reach to considerably high levels for a significant portion of the population especially those steadily using surfactant-added products.

Smith (1994) determined concentrations of chlorinated organics during cleaning of soiled shower walls with a mildew remover containing sodium hypochlorite, a surfactant, and a fragrance. He evaluated the hazard by chloroform and carbon tetrachloride by comparing (i) their concentrations to German and American permissible occupational exposure limits $\left(50 \mathrm{mg} \mathrm{m}^{-3}\right.$ for chloroform and 65 and $31 \mathrm{mg} \mathrm{m}^{-3}$ for carbon tetrachloride, respectively); and (ii) estimated exposures to "routine activities" such as drinking 2 L water a day. The referred occupational standards are much higher than indoor air standards even for total volatile organic compounds (TVOC) which range from 200 to $600 \mu \mathrm{g} \mathrm{m}^{-3}$ (Pluschke, 1999; Charles et al., 2005). Seifert (1990) proposed a target TVOC concentration of $300 \mu \mathrm{g} \mathrm{m} \mathrm{m}^{-3}$ with the following conditions: "no individual VOC should exceed $50 \%$ of the concentration allotted to its class or $10 \%$ of the TVOC concentration." $30 \mu \mathrm{g} \mathrm{m}^{-3}$ was proposed to be allotted to halocarbons. Then a target level of 200$300 \mu \mathrm{g} \mathrm{m}^{-3}$ was set (Seifert, 1999). Chronic reference exposure level is $300 \mu \mathrm{g} \mathrm{m}^{-3}$ for chloroform, which represents the airborne concentration that would pose no significant health risk to the general public (OEHHA, 2014). Furthermore, unlike Smith's (1994) comparison, the carcinogenic risk levels estimated for inhalation exposure in this study are comparable to those estimated for lifetime ingestion exposure to individual drinking water disinfection by-products (Baytak et al., 2008).

\section{Conclusions}

The present study indicated that there are several halogenated VOCs in chlorine-bleach-containing household products sold in Europe and North America. Chloroform and carbon tetrachloride were the dominating compounds having average concentrations of $9.5 \pm 29.0$ (average \pm SD) and $23.2 \pm 44.3$ (average \pm SD) $\mathrm{mg} \mathrm{L}^{-1}$, respectively. Halogenated VOC concentrations were the lowest in plain bleach, slightly higher in fragranced products and the highest in the surfactant-added products. It was found that the amounts of chlorinated VOCs formed as a result of the reactions of sodium hypochlorite and organic components are closely related to product composition.

The effect of temperature on the formation of halogenated VOCs during the use of bleach products was also investigated. It was shown that concentrations of several compounds increase substantially at high temperature applications (i.e., laundry and dishwashing). 
Estimated indoor air concentrations as a result of bleach product use indicated significant increases in indoor VOC concentrations compared to background. Results have also suggested that the carcinogenic risks may reach to considerably high levels for a significant portion of the population especially for those steadily using the surfactant-added bleach products.

Based on the results of the present study, it could be recommended that if possible the use of chlorine bleach containing household products should be avoided. If they are to be used, plain products should be preferred since they contain lower amounts of chlorinated VOCs. The products should only be used in well ventilated places in order to reduce the indoor VOC concentrations. Dermal contact should also be avoided since it could be a significant route for exposure in addition to inhalation.

\section{Acknowledgments}

We thank Remzi Seyfioglu, Cemile Yucel, and Ozge Oner (Dokuz Eylul University, Izmir, Turkey) for analyzing TOC, TN, and elemental contents of the bleach samples. We also thank Bilgehan Nas (Selcuk University, Konya, Turkey) for providing the product samples from USA.

\section{Appendix A. Supplementary data}

Supplementary data related to this article can be found at http:// dx.doi.org/10.1016/j.atmosenv.2014.04.049.

\section{References}

APHA, 1999. Standard Methods for the Examination of Water and Wastewater, 20th ed. American Public Health Association, American Water Works Association, Water Pollution Control Federation. SM 4500-Cl B.

Baytak, D., Sofuoglu, A., Inal, F., Sofuoglu, S.C., 2008. Seasonal variation in drinking water concentrations of disinfection by-products in Izmir and associated human health risks. Science of the Total Environment 407, 286-296.

Bondi, C.A.M., 2011. Applying the precautionary principle to consumer household cleaning product development. Journal of Cleaner Production 19, 429-437.

Charles, K., Magee, R.J., Won, D., Lusztyk, E., 2005. Indoor Air Quality Guidelines and Standards. National Research Council of Canada. RR-204.

Clorox, 2014. http://www.thecloroxcompany.com/products/ingredients-inside/enus/cloroxcommercialsolutions/ (accessed in January 2014.).

Edwards, R.D., Schweizer, C., Llacqua, V., Lai, H.K., Jantunen, M., Bayer-Oglesby, L. Kunzli, N., 2006. Time-activity relationships to VOC personal exposure factors. Atmospheric Environment 40, 5685-5700.

Fu, J., Qu, J., Liu, R., Qiang, Z., Liu, H., Zhao, X., 2009. Cu(II)-catalyzed THM formation during water chlorination and monochloramination: a comparison study. Journal of Hazardous Materials 170, 58-65.

Gallard, H., von Gunten, U., 2002. Chlorination of natural organic matter: kinetics of chlorination and of THM formation. Water Research 36, 65-74.

IARC (International Agency for Research on Cancer), 1999. Monographs on the Evaluation of the Carcinogenic Risks to Humans, vol. 73, p. 674.

IARC (International Agency for Research on Cancer), 1979. Monograhs on the Evaluation of the Carcinogenic Risks to Humans, vol. 20, p. 609.

Health Canada, 1998. Assessment and Management of Cancer Risks from Radiological and Chemical Hazards, 98-EHD-216 AECB INFO-0684(E) AC-5.
Legay, C., Rodriguez, M.J., Sadiq, R., Sérodes, J.B., Levallois, P., Proulx, F., 2011. Spatial variations of human health risk associated with exposure to chlorination byproducts occurring in drinking water. Journal of Environmental Management 92, 892-901.

Masters, G.M., Ela, W.P., 2008. Introduction to Environmental Engineering and Science. Prentice Hall, New Jersey.

McHugh, M.K., Kachroo, S., Liu, M., D’Amelio Jr., A.M., Dong, Q., Hong, W.K., Greisinger, A.J., Spitz, M.R., Etzel, C.J., 2010. Assessing environmental and occupational risk factors for lung cancer in Mexican-Americans. Cancer Causes \& Control 21, 2157-2164.

Nazaroff, W.W., Weschler, C.J., 2004. Cleaning products and air fresheners: exposure to primary and secondary air pollutants. Atmospheric Environment 38, 2841-2865.

Odabasi, M., 2008. Halogenated volatile organic compounds from the use of chlorine-bleach-containing household products. Environmental Science \& Technology 42, 1445-1451.

Office of Environmental Health Hazard Assessment (OEHHA), 2014. Acute, 8-hour and Chronic Reference Exposure Levels (chRELs). http://www.oehha.org/air/ allrels.html (accessed in January 2014).

Pluschke, P., 1999. Indoor air quality guidelines. In: Salthammer, T. (Ed.), Organic Indoor Air Pollutants: Occurrence - Measurement - Evaluation. Wiley-VCH, New York, p. 300.

Procter \& Gamble, 2014. http://www.info-pg.com/. (accessed in January 2014.).

Reckitt Benckiser, 2014. http://www.rbeuroinfo.com/index.php?BRAND=Cillit + Bang\&action=product_select.php\&LANGUAGE $=\mathrm{EN} \& C O U N T R Y=U S \#$. (accessed in January 2014.).

Seifert, B., 1990. Regulating indoor air. In: Indoor Air '90. Proceedings of the 5th International Conference on Indoor Air Quality and Climate, Toronto/Ottawa, vol. 5, pp. 35-49.

Seifert, B., 1999. Richtwerte fur die Innenraumluft. Die Beurteilung der Innenraumluftqualitat mit Hilfe der Summe der fluchtigen organischen Verbindungen (TVOC-Wert) (Guideline values for indoor air: the evaluation of indoor air quality using the sum of volatile organic compounds (TVOC value)). Bundesgesundheitsblatt 42, 270-278.

Seinfeld, J.H., Pandis, S.N., 2006. Atmospheric Chemistry and Physics: from Air Pollution to Climate Change. John Wiley \& Sons.

Shepherd, J.L., Corsi, R.L., Kemp, J., 1996. Chloroform in indoor air and wastewater: the role of residential washing machines. Journal of the Air \& Waste Management Association 46, 631-642.

Singer, B.C., Coleman, B.K., Destaillats, H., Hodgson, A.T., Lunden, M.M., Weschler, C.J., Nazaroff, W.W., 2006. Indoor secondary pollutants from cleaning product and air freshener use in the presence of ozone. Atmospheric Environment 40, 6696-6710.

Smith, W.L., 1994. Human and environmental safety of hypochlorite. In: Cahn, Arno (Ed.), Proceedings of the 3rd World Conference on Detergents, Global Perspectives. AOCS Publishing, pp. 183-192.

Steinemann, A.C., 2009. Fragranced consumer products and undisclosed ingredients. Environmental Impact Assessment Review 29, 32-38.

Unilever, 2014. http://www.unilever.com/PIOTI/EN/p3.asp?selectCountry=UK\& language=EN\&brandid=DOMESTOS, http://www.unilever.com/PIOTI/EN/p3. asp? selectCountry $=$ UK\&language $=$ EN\&brandid=CIF. (accessed in January 2014.).

U.S. EPA, 1987. National Usage Survey of Household Cleaning Products. US Environmental Protection Agency, Westat, Washington, DC.

U.S. EPA, 1995. Measurement of Purgeable Organic Compounds in Water by Capillary Column Gas Chromatography/mass Spectrometry (Method 524.2, Revision 4.1).

U.S. EPA, 2011. Exposure Factors Handbook. National Center for Environmental Assessment, Office of Research and Development, Report No. EPA/600/R-09/ 052F, 2011 ed. U.S. Environmental Protection Agency, Washington, DC.

U.S. EPA, 2014. Integrated Risk Information System (IRIS). http://www.epa.gov/iris/ index.html.

Vartiainen, E., Kulmala, M., Ruuskanen, T.M., Taipale, R., Rinne, J., Vehkamaki, H., 2006. Formation and growth of indoor air aerosol particles as a result of Dlimonene oxidation. Atmospheric Environment 40, 7882-7892.

Ye, B., Wang, W., Yang, L., Wei, J.E.X., 2009. Factors influencing disinfection byproducts formation in drinking water of six cities in China. Journal of Hazardous Materials 171, 147-152. 